\title{
Dinámicas de las asociaciones chinas en Perú: hacia una caracterización y tipología
}

\author{
Chinese association dynamics in Peru: \\ Toward a characterization and typology
}

\author{
CARLA TAMAGNO* \\ NORMA VELÁSQUEZ**
}

RESUMEN: La migración china al Perú es una de las más antiguas en Latinoamérica. Data del siglo XIX
y atraviesa un largo proceso de adaptación y es a través de la creación de asociaciones que los inmi-
grantes logran asimilarse y formar parte de la sociedad peruana y se manifiestan a través de su co-
mida, costumbres y valores, formando parte de la variopinta cultura peruana. En el presente artículo
se describen las dinámicas internas de las asociaciones chinas, donde a través del trabajo etnográfico,
las encuestas y entrevistas a los dirigentes de las asociaciones se ha realizado una caracterización y
una tipología de las mismas que nos permite dar cuenta del posicionamiento de las asociaciones
chinas y de un proceso de transnacionalismo basado en valores de la tradición china. En la presente
investigación se ha utilizado el análisis de redes familiares y paisanazgo para estudiar la manera de
integración con la cultura peruana. Al mismo tiempo a través de la metodología RAAKs se ha podido
ver cómo se van construyendo relaciones transnacionales y de vinculación entre lugares de origen
y destino.

PALABRAS ClaVE: organizaciones chinas en Perú, dinámicas transnacionales, asociaciones chinas en Perú, Encuesta Ciop-Perú.

ABSTRACT: Peru is a country of emigrants, but it has always been open to receiving immigrants from abroad. The Chinese began to come to Peru in the 19th Century, influencing what is today a dynamic community that fosters that country's economic development. Through their associations they have protected and promoted their traditions and achievements since that time, where all of their institutions nourish the Chinese philosophy based on principles and values that allow them to engage and live harmonically with Peruvian traditions and culture. This article describes the internal dynamics of Chinese associations, where - through ethnographic research, surveys and interviews with the founders and presidents of those associations - we successfully created a current typology of them. A central characteristic of the first generation Chinese associations is that they prioritize ethnic associations and social support, where the Chinese language and cultural diffusion are their reason for being. The second kind are the associations oriented toward social integration, made up of Chinese descendants that have created significant dynamics and investments, mainly involved in commerce and services.

KEY wORDs: Chinese organizations in Peru, transnational dynamics, Chinese associations in Peru, Peru survey.

*Profesora en la Facultad de Derecho de la Universidad San Martín de Porres en Lima y Presidenta del Observatorio Andino de Migración Interculturalidad y Codesarrollo (OAMIC).

**Doctora en Economía, Docente Asociada de la Universidad Católica Sedes Sapientie. 


\section{INTRODUCCIÓN}

$\mathrm{E}$ 1 presente artículo describe las principales características de la Comunidad China en Perú desde el punto de vista de las asociaciones constituidas por migrantes chinos y sus descendientes. Nos enfocamos en el rol de las asociaciones que llevan a cabo diversas actividades (sociales, culturales, económicas, religiosas y/o políticas) buscando mejorar su posicionamiento en la sociedad receptora y establecer vínculos de carácter transnacional con la sociedad emisora.

Este estudio forma parte del Proyecto Comparativo de las Organizaciones de Inmigrantes (Comparative Immigrant Organization Project — CIOP-) iniciado por la Universidad de Princeton en alianza con la Universidad de Miami, que tiene por objetivo analizar la presencia y actividades de las asociaciones de inmigrantes chinos en América Latina. ${ }^{1}$ El diseño de investigación ha considerado realizar un mapeo de las asociaciones chinas activas en Perú, de las cuales se seleccionaron las más representativas por tamaño y longevidad. También se aplicó el cuestionario para Líderes de Organizaciones de Migrantes; ${ }^{2}$ complementándose con entrevistas a expertos. ${ }^{3}$

${ }^{1}$ Agradecemos el apoyo de todos los colegas del equipo ciop que nutrieron este trabajo con sus aportes y comentarios, un especial reconocimiento al doctor Ariel Armony y el doctor Alejandro Portes, quienes confiaron en nosotras para la realización de este estudio.

${ }^{2}$ Agradecemos al señor Jorge Tay, presidente de la Sociedad de Beneficencia China; al señor Vicente Lo, de la Asociación Cu Con Chau; al señor Yoni Yang de la Asociación de Fujianeses en Perú; al señor Lu Dawei, de la Asociación de Empresas Chinas; y a Zhu Xiaoyan, consejera cultural de la Embajada de la República Popular China en Perú. Del mismo modo, a la señora Olinda Chang y Rolando Lau de APCH; al señor Víctor Tay, del Centro Cultural Peruano Chino; a la señora Ofelia Kocnim, expresidenta de la Asociación de Damas Chinas; al doctor Eduardo Yong Motta del Instituto Cultural Peruano Chino; a la señora Teresa Jo de Siu, gerente de la Cámara de Comercio Peruano-China; y a la doctora Martha Chú Correa, vicepresidenta de la Federación de América Latina y el Caribe de Amistad con la República Popular China, quienes nos apoyaron con información para este estudio. Sin embargo, toda la responsabilidad del mismo es nuestra.

${ }^{3}$ Nuestro reconocimiento al señor Raúl Chang y al señor Carlos Acat, de la Revista Oriental, al señor Rubén Tang, director del Instituto «Confucio» de la PuCP; a Luis García Corrochano de la UPC; al doctor Carlos Aquino de la Universidad de San Marcos y a la doctora Isabel Lausent-Herrera. Un especial reconocimiento al doctor Humberto Rodríguez Pastor por su apoyo en el conocimiento de las Asociaciones en el Valle del Jequetepeque.

$146 \frac{\text { PRIMER SEMESTRE } 2016}{\text { MIGRACIÓN Y DESARROLLO NÚM. } 26}$ 
El diseño metodológico incluyó la observación y participación de las investigadoras en la mayoría de las actividades desarrolladas por las asociaciones de la muestra, entre los meses de agosto a noviembre de 2014. En el diseño se incluyó la visita a una asociación de provincia con el fin de entender la complejidad e influencia de la migración China en el norte del Perú.

Se aplicaron 10 cuestionarios CiOp a los líderes de las organizaciones de la muestra y una entrevista en profundidad a una dirigente de la Federación Latinoamericana. Para el análisis de vinculación de actores se ha utilizado el diagrama de Raaks (Evaluación Rápida de Sistemas de Conocimiento) que es una metodología participativa de investigación-acción que trata de proporcionar información sobre los niveles de comunicación y flujo de información entre miembros de diversas asociaciones.

Las asociaciones chinas se han constituido en uno de los grupos con mayor influencia en la sociedad peruana; se calcula grosso modo que hasta 10 por ciento de la población peruana tendría raíces chinas, o estaría indirectamente vinculada a ellas.

Se carece de registros que puedan indicar el número exacto de chinos y descendencia en el Perú, sin embargo algunos autores señalan que durante el siglo XIx llegaron a Perú alrededor de 100,000 chinos (Rodríguez, 2000). Fernando de Trazegnies, considerando esta cifra y asumiendo un promedio de descendientes por generación de dos individuos, calculaba que hacia 1986 más de 3 millones de personas en Perú llevaban sangre china (Trazegnies, s/f.: 7-10).

Según los datos de ciudadanos extranjeros residentes en Perú, desarrollados por la Superintendencia de Migraciones en el periodo 2009-2015, se registraron 52,014 ciudadanos, de ellos la comunidad china ocupa el quinto lugar con 3,127.

En cuanto a las características de los ciudadanos chinos residentes en el país destacan que 60.6 por ciento son hombres (39.4 por ciento mujeres); sobre su estado civil en su mayoría son casados ( 55.5 por ciento) seguido de los solteros en un 43.7 por ciento, los mismos que se concentran en un mayor porcentaje en las edades productivas. Sobre su calidad migratoria, 42.4 por ciento son trabajadores, 25.1 por ciento ha declarado ser inmigrante, 
10.4 por ciento inversionista, el resto declaró otras categorías ocupacionales. Sobre su profesión 27.7 por ciento son empleados, 15.9 por ciento empresarios, 13.2 por ciento amas de casa, 9.8 por ciento comerciante principalmente.

Sobre su calidad migratoria, 92.1 por ciento cuenta con trámite de residencia vigente, 6.4 por ciento con vigencia vencida y menos de 2 por ciento son irregulares.

\section{GRÁFICA 1}

Ciudadanos extranjeros residentes en Perú según país de nacionalidad, 2009-2015*

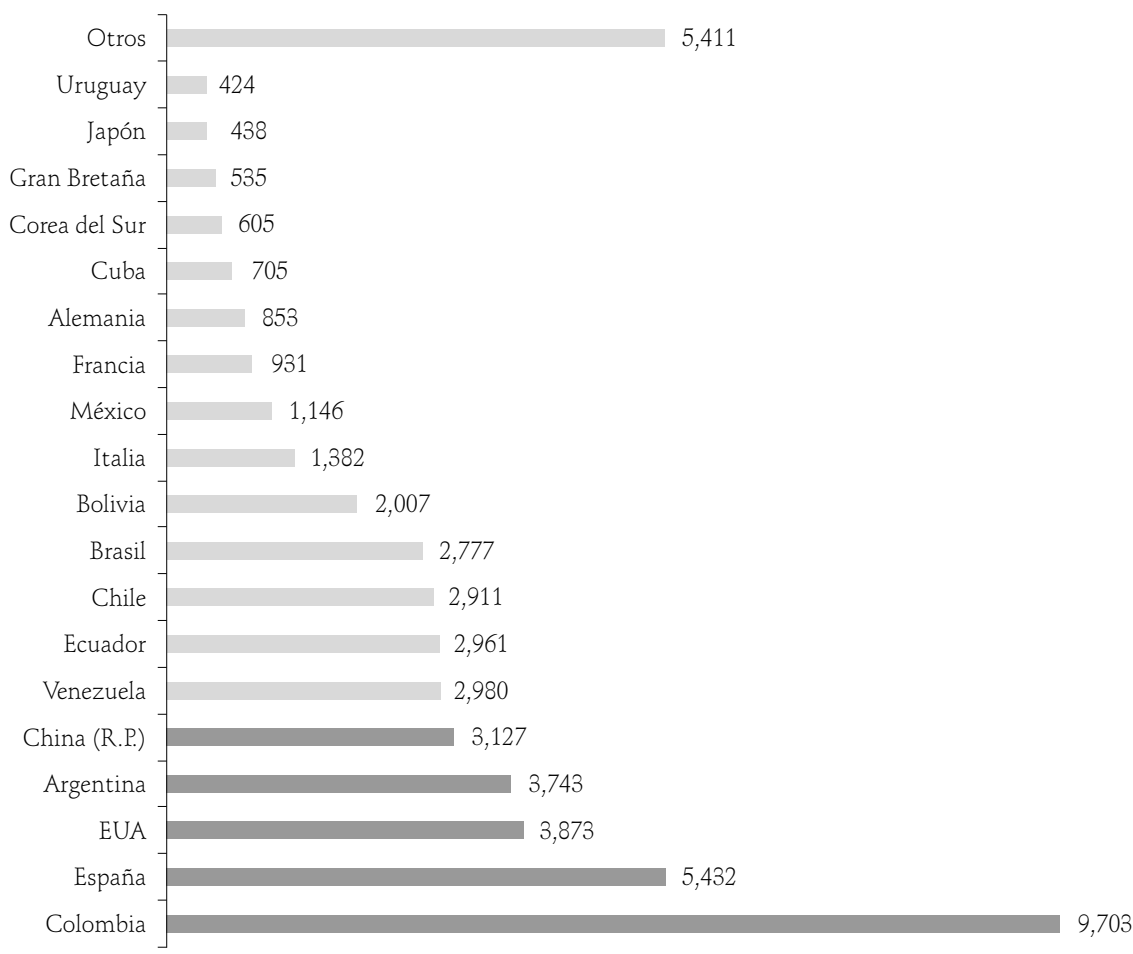

* Año de inscripción del 01ene2009 al 20nov2015.

Fuente: Información extraída de la Base de Dat + +os Migraciones el 24-11-2015.

$148 \frac{\text { PRIMER SEMESTRE } 2016}{\text { MIGRACIÓN Y DESARROLLO NÚM. } 26}$ 
En la migración China hacia Perú se pueden distinguir hasta cuatro oleadas, caracterizadas por diversos perfiles de migrantes. La primera se inicia con la migración de culíes que provenían principalmente de Guandong, y se da entre 1849 y 1872 , estimulada por la coincidencia de alta demanda de mano de obra en Perú y crisis en China. De acuerdo con diversos estudios, llegaron aproximadamente cien mil trabajadores contratados para trabajar en las haciendas de la costa y en las islas guaneras, viviendo en condiciones infrahumanas, con contratas de 8 años, para después ser liberados. Esta situación finaliza en 1874 con la firma en Tientsin de un Tratado de Amistad, Comercio y Navegación entre Perú y China (Steward, 1976). Los culíes liberados migraron hacia Lima para dedicarse a actividades de comercio, servicio y la atención de pequeñas fondas llamadas «Chifas» constituyendo el Barrio Chino en la calle Capón y los alrededores del mercado Central de Lima (Rodríguez, 2000; Lausent-Herrera, 2011).

La segunda oleada se da a finales del siglo xIX y principios del xx, con el arribo de comerciantes de Hong Kong y California, llegados con capitales que invirtieron en prósperos negocios y convirtiéndose en gestores de las primeras asociaciones desde mediados de la década de 1880 y que apoyaron a su colonia a integrarse al Perú (Sociedad Central, s/f; Derpich, 1999; Rodríguez, 2000; Lausent-Herrera, 2011, 2012).

La tercera oleada de migración más reciente tiene lugar durante los años ochenta, está compuesta por taiwaneses y chinos continentales que buscan alternativas al sistema comunista, y también se ubican predominantemente en el sector comercial y empresarial. En estos años se acentúa la llegada de los chinos desde la provincia de Fujian, muchos de los cuales son irregulares. La cuarta oleada de migración transcurre desde finales de los noventa hasta la actualidad, y se caracteriza por la migración de trabajadores de las empresas chinas transnacionales que tienen inversiones en Perú, predominando los técnicos especializados cuya radicación en Perú es transitoria (Lausent-Herrera, 2012).

Desde que los chinos arribaron a Perú construyeron asociaciones con diferentes finalidades, siendo la principal el apoyo social, cultural, religioso y económico. Se ha identificado la formación, durante el periodo 1867-2014, 
de 229 asociaciones chinas situadas en Lima y Provincias, de las cuales menos de 10 por ciento están activas actualmente. Es importante recalcar que todas las asociaciones chinas a nivel nacional están vinculadas con la Beneficencia China, que tiene una estructura federativa y es una de las instituciones más respetadas de la Comunidad China en Perú. De otro lado, a raíz de la firma del TLC entre China y Perú aproximadamente 56 empresas se han posicionado en diferentes actividades económicas, especialmente en la minería, y están afiliadas a la Asociación de Empresas Chinas en el Perú, que mantiene vínculos y coordina actividades con la Sociedad Central de Beneficencia China y con las Asociaciones de Tusanes en Perú.

\section{Caracterización y tipología de las asociaciones chinas EN LA ACTUALIDAD}

Basados en las actividades que predominantemente desarrollan, es posible clasificar a las asociaciones chinas actualmente activas en Perú en tres categorías:

- Asociaciones chinas étnicas y de apoyo social. Son las asociaciones creadas por inmigrantes de primera generación, y tienen como principal característica que sus miembros hablan el idioma chino entre ellos. Este grupo de asociaciones se define por abarcar un abanico amplio de actividades y están abiertas a todos los inmigrantes que llegan de China y quieren residir en Perú. Dentro de esta categoría encontramos diversos sub-tipos que desarrollan actividades en ámbitos diversos (empresarial, religioso, asistencia mutua, deportiva, etcétera).

- Asociaciones de Tusan para la integración y difusión intercultural. Son organizaciones creadas por y para los descendientes de chinos de segunda y tercera generación (Tusan deriva de Tusheng, que significa «nacido en Perú»). El requisito fundamental para participar de las mismas es que el miembro socio o su cónyuge lleve un apellido chino. Estas organizaciones son principalmente de integración y difusión sociocultural (Lausent-Herrera, 2009).

$150 \frac{\text { PRIMER SEMESTRE } 2016}{\text { MIGRACIÓN Y DESARROLLO NÚM. } 26}$ 
- Asociaciones de Amistad entre Perú y China para la promoción de inversiones y cultura. Está conformado por las asociaciones peruano-chinas que incluyen tanto socios chinos como peruanos y tienen el propósito de promover relaciones de amistad entre ambos países. Creadas a partir de los años sesenta, son de carácter cultural y económico y se caracterizan por haber canalizado la cooperación china a diversas obras públicas (sociales y culturales) en Perú.

\section{GRÁFICA 2}

Perú: tipología de asociaciones chinas en Perú, 2014

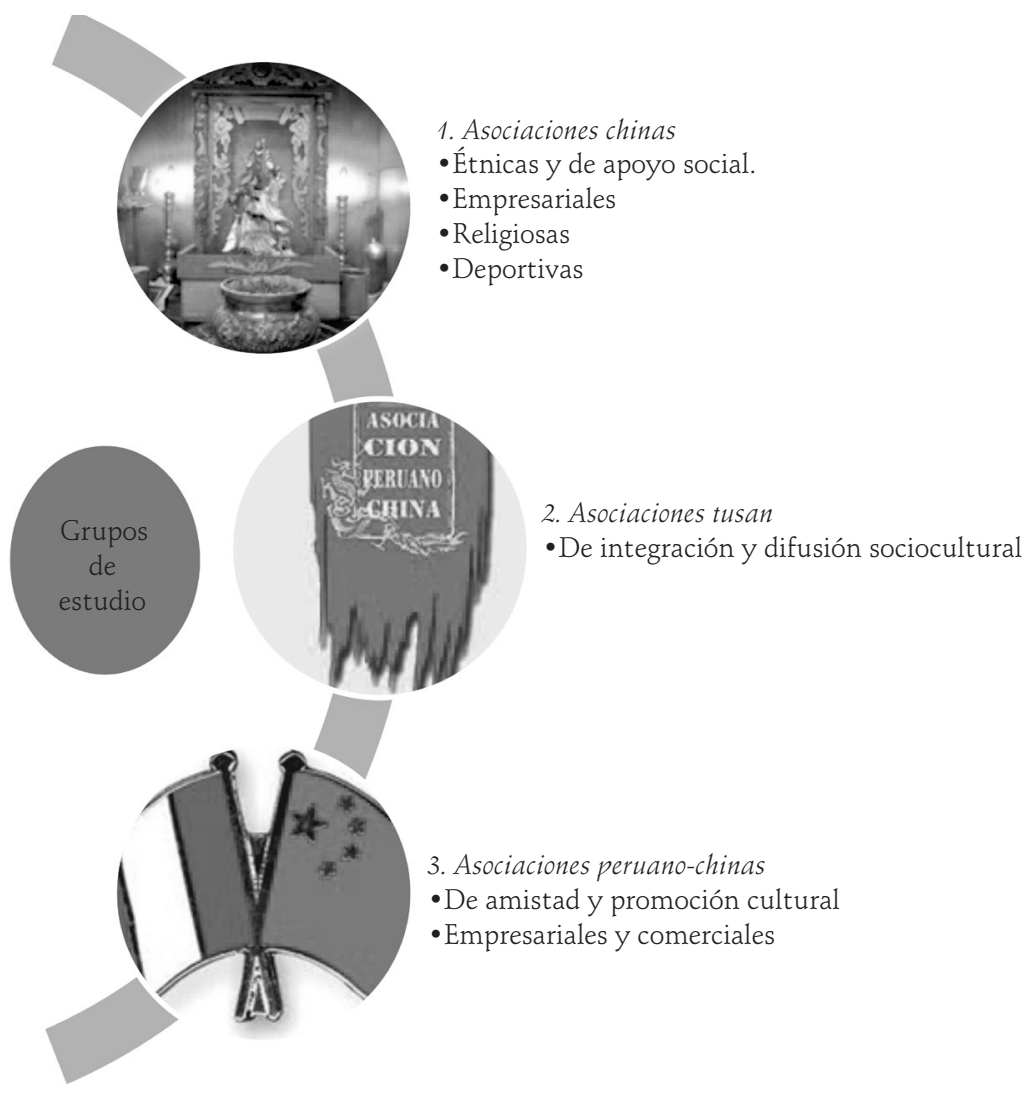

Fuente: Elaboración propia. 
TABLA 1

Perú: Objetivos de las asociaciones chinas entrevistadas, 2014

\begin{tabular}{|c|c|}
\hline NOMBRE DE LA ASOCIACIÓN & OBJETIVO \\
\hline Cu Con Chau & Étnico-religioso y de apoyo social \\
\hline Sociedad de Beneficencia China ( $\mathrm{SBCH}$ ) & Étnico-religioso y de apoyo social \\
\hline Asociación Fujian (AF) & Étnico y de apoyo social \\
\hline Asociación de Empresas Chinas del Perú (AECP) & $\begin{array}{l}\text { Empresarial dirigida a la integración y fortaleci- } \\
\text { miento de sus empresas en el Perú }\end{array}$ \\
\hline $\begin{array}{l}\text { Asociación de Damas de la Colonia China en el } \\
\text { Perú (ADCCH) }\end{array}$ & Integración-Apoyo Social \\
\hline Centro Cultural Peruano China (ССРCH) & Integración y difusión sociocultural \\
\hline Asociación Peruano Chino (APCH) & Integración y difusión sociocultural \\
\hline Instituto Cultural Peruano Chino (ICPC) & $\begin{array}{l}\text { Promoción de relaciones de amistad a través de la } \\
\text { cultura }\end{array}$ \\
\hline Cámara de Comercio Peruano Chino (ССРCH) & Promoción económica y comercial binacional \\
\hline $\begin{array}{l}\text { Federación de América Latina y el Caribe de } \\
\text { Amistad con la República Popular China (ACHILAC) }\end{array}$ & Relaciones de amistad \\
\hline Cheng Lhing Club (Provincias) & Integración social \\
\hline
\end{tabular}

Fuente: Elaboración propia.

En la encuesta CIOP 2014 se indica la importancia del factor étnico en la conformación de las organizaciones, que tienden a estructurarse de acuerdo con el lugar de origen y parentesco de sus miembros, con el objetivo primario de ayudar a sus connacionales tanto en origen como destino (71 por ciento asociaciones chinas y 42.9 por ciento asociaciones tusanes). Otras instituciones promueven las actividades socioculturales y la celebración de fiestas tradicionales (42.9 por ciento para ambos tipos de asociación), generando a través de la difusión cultural redes sólidas con un importante capital social. El objetivo de brindar ayuda económica a través de los panderos define un tercer grupo de asociaciones (28.6 por ciento asociaciones tusanes y 14.3 por ciento asociaciones chinas).

La edad promedio de los miembros supera los 40 años tanto entre las asociaciones de oriundos como entre las tusanes. El promedio de edad es más bajo en el caso de la Sociedad Fujian, que acoge a inmigrantes más recientes (60 por ciento de sus asociados tiene entre 25 y 39 años de edad, constituyendo el grupo más joven de las asociaciones chinas). Cabe destacar

$152 \frac{\text { PRIMER SEMESTRE } 2016}{\text { MIGRACIÓN Y DESARROLLO NÚM. } 26}$ 
que APCH se diferencia por contar con un grupo de jóvenes que juega un papel dinamizador importante. Los niveles de educación formal son más altos entre los miembros de las asociaciones tusanes, que incluyen a individuos con estudios superiores e incluso de postgrado. Esto se ve reflejado en los perfiles ocupacionales de los miembros, con predominio de trabajadores no calificados y calificados entre las asociaciones chinas y tusanes, respectivamente. En ambos casos, sin embargo, los empresarios y dueños de negocios muestran un mayor involucramiento en las actividades de la asociación.

TABLA 2

Perú: comparativo entre características de socios de asociaciones chinas y tusanes, 2014 (porcentaje)

\begin{tabular}{|c|c|c|c|c|c|c|c|}
\hline \multirow[b]{2}{*}{ CARACTERÍSTICAS } & \multicolumn{4}{|c|}{ ASOCIACIONES CHINAS } & \multicolumn{3}{|c|}{ ASOCIACIONES TUSANES } \\
\hline & $\mathrm{SBCH}$ & $\begin{array}{l}\text { CHENG } \\
\text { LHIN } \\
\text { CLUB }\end{array}$ & FUJIAN & $\begin{array}{l}\text { CUCON } \\
\text { CHAU }\end{array}$ & $\mathrm{APCH}$ & $\mathrm{CCPH}$ & $\mathrm{ADCH}$ \\
\hline \multicolumn{8}{|l|}{ Edad } \\
\hline Menos de 25 años de edad & & 15.0 & 10.0 & 10.0 & 10.0 & 10.0 & \\
\hline De 25 a 39 años de edad & 10.0 & 15.0 & 60.0 & 20.0 & 20.0 & 10.0 & \\
\hline De 40 a 54 años de edad & 70.0 & 30.0 & 30.0 & 50.0 & 30.0 & 50.0 & 30.0 \\
\hline Más de 55 años de edad & 20.0 & 40.0 & & 20.0 & 40.0 & 30.0 & 70.0 \\
\hline \multicolumn{8}{|l|}{ Escolaridad } \\
\hline Hasta secundaria completa & 70.0 & 70.0 & & 90.0 & 25.0 & 40.0 & 90.0 \\
\hline Superior/ postgrado & 30.0 & 30.0 & & 10.0 & 75.0 & 60.0 & 10.0 \\
\hline \multicolumn{8}{|l|}{ Ocupación } \\
\hline $\begin{array}{l}\text { Trabajadores manual (agricultura, } \\
\text { fábricas, restaurantes, hoteles, etc.) }\end{array}$ & & 20.0 & 20.0 & 10.0 & 10.0 & 5.0 & \\
\hline Empleados de oficina & & 20.0 & & & 10.0 & 5.0 & \\
\hline Vendedores & & 10.0 & 10.0 & & & & \\
\hline Técnicos y/o profesionales & 10.0 & 20.0 & & 10.0 & 30.0 & 20.0 & 20.0 \\
\hline $\begin{array}{l}\text { Dueños de negocios o epresas } \\
\text { Amas de casa }\end{array}$ & 90.0 & 20.0 & 70.0 & 80.0 & 50.0 & 70.0 & 80.0 \\
\hline Estudiantes & & 10.0 & & & & & \\
\hline
\end{tabular}

Nota: La tabla considera como un total a 7 encuestas CIOP de asociaciones chinas, tusanes y asociaciones que promueven relaciones Perú-China. La tabla se ha desarrollado con base en una respuesta indirecta, es decir, no se han entrevistado a cada uno de los socios, sino el encuestado ha señalado un cálculo grueso del total de socios de su institución.

Fuente: Perú. Cuestionario Líderes de Organizaciones de Migrantes Asiáticos. Comparative Immigrant Organization Project 2014. Miami University and Princeton University. III Trimestre.

Fuente: Elaboración propia. 
Asociaciones chinas

La Sociedad de Beneficencia China representa a 11 asociaciones de la provincia de Guandong y a 10 asociaciones de chinos a nivel nacional.

La Sociedad Central de Beneficencia China ( $\mathrm{SBCH}$ ) de Perú fue fundada por ocho grandes comerciantes chinos en 1882 (Sociedad Central, s/n), contando con el apoyo del diplomático acreditado en el país (Derpich, 1999: 79). Una obra importante de la SBCH fue la creación de escuelas para hijos de inmigrantes chinos, fusionadas en 1962 en el Colegio Peruano-Chino.

Se han identificado 10 organizaciones chinas de beneficencia con alcance local, en Chiclayo, Huacho, Huánuco, Huaral, Ica, Mollendo, Paita, Pisco, Piura y Trujillo. Si bien los procesos de surgimiento son en todos los casos mal conocidos, todas cumplían con la función principal de ayudar a los exculíes, de los cuales ya en los años sesenta una fracción importante se encontraba en situaciones de pobreza o dedicados a mendigar, carentes de acceso a servicios asistenciales.

La SBCH mantiene estrechos vínculos con otras sociedades de beneficencia china en América Latina, principalmente con Brasil y Ecuador, donde hay miembros descendientes de los migrantes chinos de Hong Kong y California.

La Asociación de Empresas Chinas en el Perú se fundó en 2011 con el apoyo de la Embajada de China, abarcando inicialmente 43 empresas que operaban en sectores diversos (minero, hidrocarburos, telecomunicaciones, comercialización, finanzas, textil, fabricación de equipos y de servicios logísticos). Como objetivos centrales, la asociación procura profundizar la comunicación entre sus afiliados, de modo que ponga su experiencia al servicio de las nuevas empresas chinas que se instalan en el país, mejorar el acceso de éstas a las instituciones gubernamentales, y promover las relaciones comerciales bilaterales e inversiones.

La AECP realiza además diversas actividades de orden social y muchas de carácter cultural en alianza estratégica con la SBCH y las asociaciones tusanes.

$154 \frac{\text { PRIMER SEMESTRE } 2016}{\text { MIGRACIÓN Y DESARROLLO NÚM. } 26}$ 


\section{GRÁFICA 3}

Estructura de la $\mathrm{SBCH}$, sus relaciones y vínculos entre beneficencias en Perú y América Latina, 2015

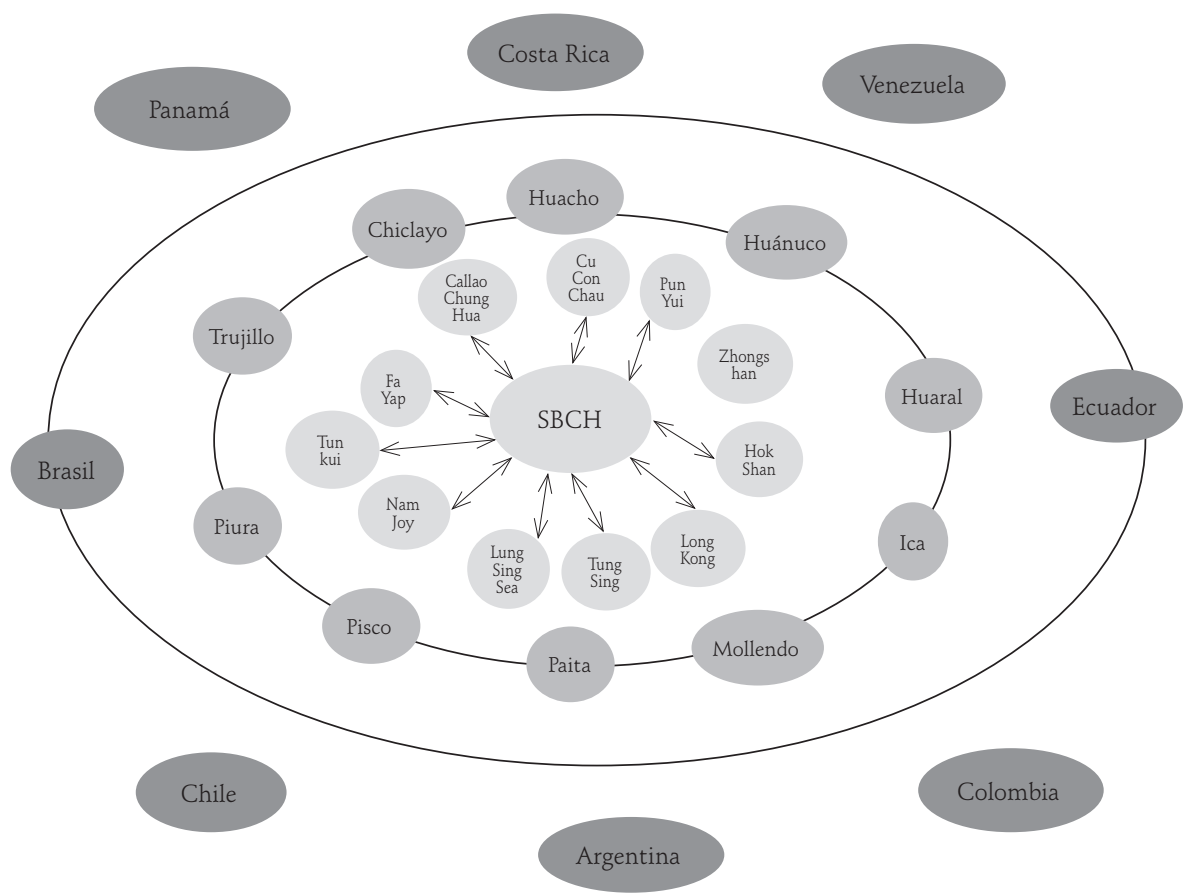

Fuente: Elaboración propia.

Las asociaciones de Tusan

Si bien hay estudios que señalan que había una diferencia cultural marcada entre los padres de origen chino y sus hijos nacidos en Perú (Lausent-Herrera, 2009), otros destacan el papel jugado por los tusan en la integración entre inmigrantes chinos y las sucesivas generaciones de sus descendientes nacidos en Perú (García-Corrochano y Tang, 2011).

Las asociaciones tusan se caracterizan por promover la integración de los peruano-chinos a través de actividades socioculturales que fomenten su 
conocimiento e identificación con la cultura china. Las más representativas son la Asociación Peruano-China, el Centro Cultural Peruano Chino y el Comité de Damas Chinas.

Asociaciones peruano-chinas: amistad y promoción cultural, comercial y empresarial

Las diversas asociaciones agrupadas en esta categoría datan de los tardíos años sesenta o de fechas más recientes. Compuestas por socios de origen chino y peruano, apuntan al fortalecimiento de las relaciones bilaterales, combinan actividades de naturaleza económica y cultural, y proveen el principal canal para el flujo de la cooperación china destinada a proyectos de índole diversa (promoción de la salud y educación, difusión cultural, apoyo a actividad empresarial). Sin perjuicio de esa comunidad de objetivos generales, sus orígenes y conexiones pueden ser muy diversos. Así, por ejemplo, mientras que el Instituto Cultural Peruano-Chino (ICPCH), creado en 1968, emergió de una iniciativa local apoyada por algunos miembros prestigiosos de la élite cultural peruana, la filial peruana de la Asociación de Amistad Chino-Latinoamericana y Caribeña (Aachilac) es parte de una red de alcance regional, creada en 1960 y a su vez miembro de la Asociación de Amistad del Pueblo Chino con el Extranjero, una iniciativa informal, pero resultado directo de esfuerzos por superar el aislamiento diplomático causado por la falta de reconocimiento internacional a la República Popular China.

A su vez, las asociaciones de promoción comercial y empresarial responden a la iniciativa de empresarios chinos y peruanos interesados en incrementar los flujos de inversión y comercio entre los dos países. Los representantes de este tipo de asociaciones son la Cámara de Comercio China en el Perú y la Asociación de Empresas Chinas (AECH). De creación reciente (2001), la Cámara de Comercio China en el Perú nuclea a un número importante de empresas (500) —entre las que figuran algunas corporaciones chinas de importancia y los principales bancos y empresas de exportación e importación peruanos-y mantiene conexiones con el China Council for the Promotion of International Trade. El CCPIT tiene entre sus principales servicios un foro

$156 \frac{\text { PRIMER SEMESTRE } 2016}{\text { MIGRACIÓN Y DESARROLLO NÚM. } 26}$ 
social para redes de negocios entre profesionales de los miembros del CCPIT, además de un canal de interacción entre las empresas socias y las autoridades chinas.

\section{Construcción de asociaciones de migrantes chinos en Perú A TRAVÉS DEL ANÁLISIS DE REDES}

Redes familiares y organizaciones de inmigrantes juegan un papel importante en la dinámica de la diáspora china en general; en el caso peruano, la evidencia sugiere que han sido relevantes como facilitadores de la movilidad social ascendente de los inmigrantes chinos. Encontramos útil para nuestro análisis del caso apoyarnos en aquellos autores que han aplicado las teorías de redes al estudio de procesos migratorios. Esta perspectiva se centra en la identificación de procesos de construcción de redes transnacionales que integran sucesivas cohortes de migrantes y no migrantes, y al operar como vehículos de circulación y reproducción de capital social facilitan la integración de los inmigrantes en las sociedades receptoras (Douglas y Fe, 1998; Massey et al., 2000).

Para entender el proceso de vinculación y construcción de redes en el interior de las asociaciones chinas se ha utilizado la metodología Raaks, que mide la magnitud de la vinculación entre actores a partir de un diagrama que mapea sus interacciones. Hemos asignado valores entre 0 y 3 , donde el puntaje igual a cero indica que se carece de vinculación entre actores, 1 existe una relación entre las asociaciones, 2 existe una vinculación importante entre asociaciones, y 3 la relación es intensa y de alta confianza.

El diagrama muestra que son las asociaciones étnicas, entre ellas principalmente la $\mathrm{SBCH}$, las que mantienen vinculación más estrecha con el país de origen y la embajada china. De igual forma, las asociaciones empresariales (AECP y Capechi) tienen vínculos importantes con el sistema financiero y las cámaras de comercio provinciales en China. El diagrama muestra la influencia que existe entre los ministerios chinos de educación, cultura, salud y seguridad, entre otros, con las instituciones peruanas promovidas por las asociaciones de amistad y la embajada. 
El Dr. Guillermo Dañino en su libro Enciclopedia de la cultura china (Centro Cultural Peruano Chino, 2013) destaca 8 valores que son difundidos por el estado chino en la educación y en las políticas a sus diásporas en el exterior. Estos valores son: sentimientos patrióticos, integridad, diligencia y frugalidad, modestia, honestidad y fidelidad, ansia de aprender, solidaridad y honrar a los maestros; son importantes valores que se cultivan en la sociedad China y que les ha permitido el desarrollo del país. ${ }^{4}$

\section{GRÁFICA 4}

Perú: redes de vinculación de la sBCH, 2014

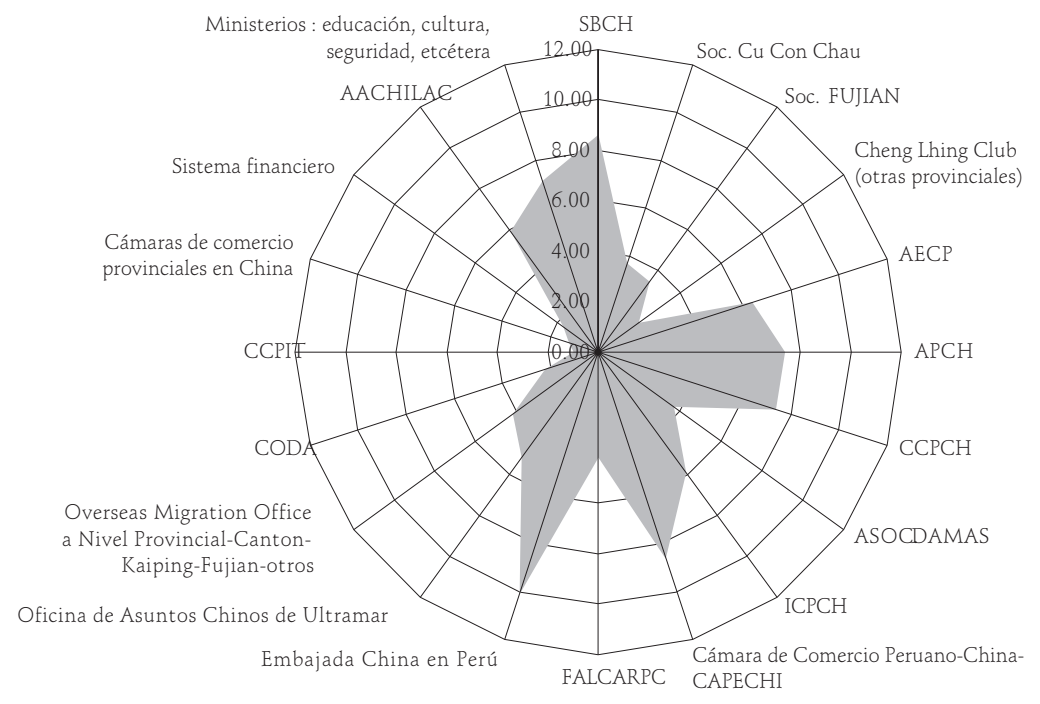

Fuente: Elaboración propia.

Al estudiar a las asociaciones chinas podemos ver que sus redes se fortalecen con los años, en la medida en que están basadas en la confianza recíproca. Nuestra hipótesis es que esta confianza se alimenta de una historia

${ }^{4}$ Dañino (2013: 566-567) cita el libro Common Knowledge about Chinese Culture, editado por The Overseas Chinese Affairs Office of the State Council and The China Overseas Exchanges Association (Pekín, 2001), el cual está dirigido a fortalecer los lazos de las comunidades migrantes con el Estado Chino. Véase http://english.gov.cn/state_council/2014/10/01/ content_281474991090995.htm

$158 \frac{\text { PRIMER SEMESTRE } 2016}{\text { MIGRACIÓN Y DESARROLLO NÚM. } 26}$ 
común en la que los más ricos han apoyado a los más pobres basados en el principio de reciprocidad y apoyo mutuo. Al analizar a la diáspora china en el Perú se encuentra dos maneras de interpretar sus valores centrales que los mantienen unidos a través de la práctica cultural ancestral y de la difusión de los valores promovidos por las instituciones del Estado chino que trabajan con la diáspora y que recalcan el fortalecimiento de la cultura china en sus organizaciones.

Como apreciamos en el diagrama de vinculación, la relación del Estado chino, a través de su embajada, con las asociaciones chinas en Perú es muy fuerte y se ha consolidado a través del tiempo. La SBCH, por ejemplo, recibió sólo durante 2013 a 25 delegaciones de distintos organismos de China. Sus 11 sociedades miembros son las instituciones referentes de las Oficinas de Chinos de Ultramar que existen en cada provincia china y monitorean las comunidades chinas en el exterior. Las Oficinas de Chinos de Ultramar de cada provincia dependen del Consejo de Estado de la República Popular de China, que es una oficina administrativa que asiste al primer ministro en los asuntos relacionados con los chinos de ultramar, y visitan cada una de las sociedades anualmente.

El método usado permite detectar una serie de vínculos relevantes que gravitan en torno a la $\mathrm{SBCH}$ :

- Con las instituciones del gobierno chino (ministerios) vinculadas a la educación y la cultura (lazos transnacionales);

- Con asociaciones empresariales y organizaciones tusan principalmente a través de actividades socioculturales;

- La casa cultural peruano-china mantiene una relación directa de trabajo con las asociaciones tusan evidenciando lazos de confianza;

- Con las asociaciones de beneficencia china a nivel nacional (10);

- Con la embajada china en Perú, que le asegura vínculos estrechos con su país de origen, permitiendo desarrollar actividades de promoción cultural en Perú;

- Las otras sociedades de beneficencia de países extranjeros como Brasil, Ecuador con quienes mantienen una vinculación estrecha. Con Panamá, Chile, Argentina, Colombia, Venezuela y Costa Rica existen vínculos más débiles. 
La $\mathrm{SBCH}$ es el socio estratégico de todas las organizaciones chinas y tusanes en Perú. Su historia y los roles que ha cumplido simultáneamente como institución benefactora y protectora de la comunidad china en Perú, y como entidad promotora de la conservación de las tradiciones y cultura chinas en Perú han cimentado su posicionamiento sólido en las sociedades peruana y china.

\section{Relaciones transnacionales}

La Aachilac (Asociación de Amistad China Latinoamericana y Caribeña) ha jugado un rol central en el establecimiento de relaciones diplomáticas con el Perú a través de sus asociaciones de amistad como el Instituto Cultural Peruano Chino (ССCH).

La gráfica 5 destaca el grado de vinculación de la Capechi con 22 cámaras de comercio de las distintas provincias de China, así como con instituciones gubernamentales nacionales y todas las Oficinas de Chinos de Ultramar en cada provincia de Cantón y en las provincias de Fujian.

Por su parte, la Asociación de Empresas Chinas tiene 60 empresas socias con sede en China y relacionadas con los sectores de mayor crecimiento económico del Perú, además de vinculadas con el sistema financiero chino y con el Comité de Desarrollo de las Empresas Chinas en Ultramar (Coda) - perteneciente a la Comisión de Desarrollo Nacional y Reforma Nacional de China.

El Instituto Cultural y el Centro Cultural Peruano-Chino están vinculados a la Federación de América Latina y el Caribe de Amistad con la República Popular China, y a la Chinese People Association for Friendship with Foreign Countries.

Se observa que la embajada china es la institución con vínculos más densos entre el Perú y China, seguida de la Sociedad de Beneficencia China, cuyos vínculos con el gobierno chino se dan principalmente en materia de educación, salud y cultura — esto último reflejado en la presencia y expansión de los Institutos "Confucio» en el Perú (no han sido incluidos en el estudio).

$160 \frac{\text { PRIMER SEMESTRE } 2016}{\text { MIGRACIÓN Y DESARROLLO NÚM. } 26}$ 


\section{GRÁFICA 5}

Perú: tipología de redes transnacionales

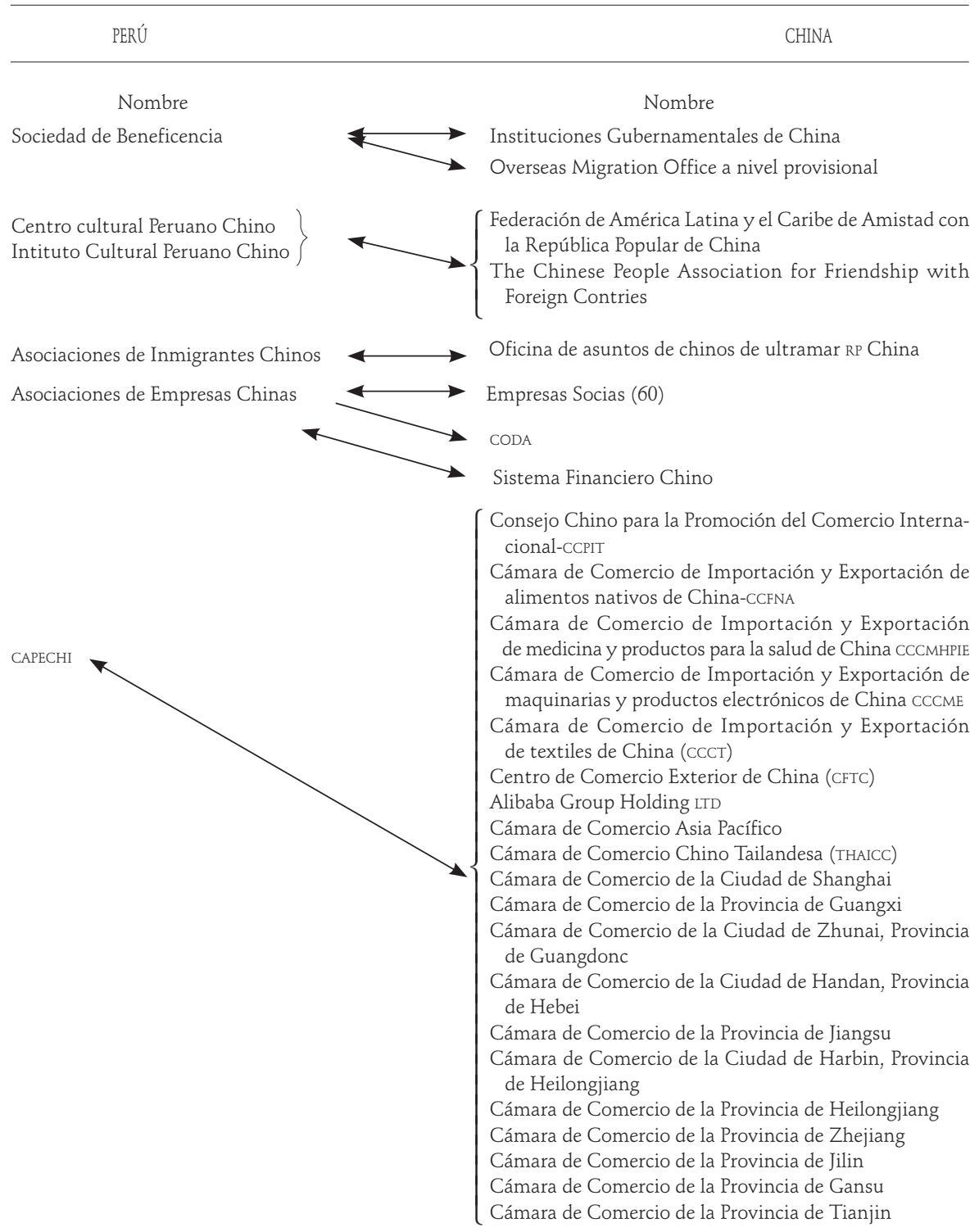

Fuente: Elaboración propia. 
Las asociaciones chinas estudiadas tienen un mayor contacto con China a través de relaciones transnacionales articuladas por las asociaciones empresariales como la Capechi y la AECP. La Capechi es una de las organizaciones peruana más conectadas en China, gracias a que su organización referente en China es el Consejo Chino para la Promoción del Comercio Internacional (CCPIT). Esta instancia ha permitido conectar a la Capechi con todas las cámaras de comercio de las provincias chinas, con las que actualmente tiene relaciones de negocios muy fluidas.

Por otro lado, la Asociación de Empresas Chinas se ha convertido en la asociación transnacional del Estado chino más importante para los empresarios chinos con actividades de negocios en Perú, que está a cargo de negociar y apoyar a las empresas inversionistas chinas en Perú con el apoyo de la Asociación para el Desarrollo de China en el Exterior (Coda).

\section{Conclusiones}

Las asociaciones chinas en Perú son las más representativas de la cultura China y han logrado un gran prestigio y reconocimiento en el tiempo. Actualmente es uno de los colectivos más sólidos que se encuentra en un proceso de fortalecimiento y renovación de cuadros dirigentes con la nueva llegada de jóvenes. En los últimos años la comunidad china ocupa el quinto lugar de la migración extranjera en Perú; donde la mayoría son empleados, empresarios y comerciantes jóvenes, donde 60.6 por ciento son varones y 39.4 por ciento; donde 55.5 por ciento están casados.

La gran mayoría de las asociaciones chinas son dinámicas y muchas de ellas han sido de carácter temporal, teniendo una utilidad estrechamente dependiente de los concretos contextos históricos de sus fundaciones respectivas y de los específicos intereses y demandas de sus fundadores. Muchas de éstas dejaron de funcionar porque no fueron renovadas, o terminaron de cumplir con sus objetivos, lo que hace imprescindible documentar los procesos históricos de los que emergieron para entender sus dinámicas particulares.

$162 \frac{\text { PRIMER SEMESTRE } 2016}{\text { MIGRACIÓN Y DESARROLLO NÚM. } 26}$ 
De las asociaciones analizadas podemos concluir que las redes familiares con un lugar de origen común tuvieron un rol estratégico en la integración social, económica, política, cultural y empresarial de los chinos y sus descendientes en la sociedad peruana, facilitando un posicionamiento importante que se extiende hasta nuestros días.

Actualmente las asociaciones chinas en el Perú son socioétnicas, de integración, empresariales y de amistad. Mantienen una estrecha relación de camaradería entre ellos, se consideran «socios estratégicos». En este sentido, el desarrollo de redes de confianza es fundamental. El trabajo en el interior de las asociaciones es voluntario y llevar un cargo de liderazgo es «un honor» e implica prestigio para los dirigentes, principalmente para las primeras y segundas generaciones. La embajada fortalece estos vínculos culturales con el reconocimiento permanente al trabajo de sus miembros y, a la vez, promueve y refuerza sentimientos de lealtad y patriotismo hacia China. Diversas instituciones del Estado chino contribuyen al fortalecimiento de esos vínculos.

\section{ACRÓNIMOS}

ACHILAC Asociación de Amistad China con los países extranjeros

$\mathrm{ADCH} \quad$ Asociación de Damas de la Colonia China

ADEX Asociación de Exportadores

AECP Asociación de Empresas Chinas en el Perú

APCH Asociación Peruano China

APEC Foro de Cooperación Económica Asia-Pacífico

CAPECHI Cámara de Comercio Peruano Chino

$\mathrm{CCPCH}$ Centro Cultural Peruano Chino

CCPIT Consejo Chino para la Promoción de Comercio InternacionalChina Council for the Promotion of International Trade

CNPC China National Petroleum Corporation

CODA Asociación para el Desarrollo de China en el Exterior

ICBC Banco Industrial y Comercial de China

ICPCH Instituto Cultural Peruano Chino

$\mathrm{SBCH} \quad$ Sociedad de Beneficencia China

TLC Tratado de Libre Comercio 


\section{Bibliografía}

Anderson, B. (2001). «Multiple Transnationalisms: Space, The State and Human Relations». Documento presentado en el grupo de trabajo SSRC y ESRC sobre migración internacional. EUA: Princeton University.

Balarezo Carbajal, A. A. (1920). Los editores. Guadalupe: El Modelo.

Banco Mundial (2012). Informe sobre Desarrollo Mundial 2013-Empleo. Washington, D.C.

Beneficencia China del Callao (2011, 31 de marzo). < http://beneficiachinacallaoperu. blogspot.com/>.

Congreso de la República (21 de noviembre de 2014). Congreso de la República. Recuperado de <https://soundcloud.com/radiocongreso $>$.

Dañino, G. (2013). Enciclopedia de la Cultura China. Beijing, China: Ediciones de Lenguas Extranjeras Ltda.

Derpich, W. (1999). El otro lado azul. Empresarios chinos en el Perú (1890-1930). Lima: Fondo Editorial del Congreso del Perú.

Douglas, G. y C. Fe (1998). «Redes migratorias y la formación de sistema de migración». En M. Graciela, Cruzando Fronteras: Migraciones en el Sistema Mundial. Madrid: Fundación Hogar del Empleo.

El Nacional (1876). El Nacional, XI. 4 de agosto, p. 4. (1888). "Constucción del Colegio Chino». 14 de mayo, p. 1.

FMI (2014). World Economic Outlook. Washington, D.C.

Fundación Amistad Peruano-China (2014). Fundación Amistad Peruano-China. $<$ http://fundacionamistadperuanochina.org/relaciones-comerciales-y-cooperacion-economica-y-tecnologica.html $>$.

García-Corrochano, L. y R. Tang (2011). Las Relaciones entre el Perú y China. Lima: PUCP.

Lausent-Herrera, I. (2009). "Tusan (tusheng) and the Changing Chinese Community in Perú». Journal of Chinese Overseas, 5 (5).

(2011). "The Chinatown in Peru and the Changing Peruvian». Journal of Chinese Overseas, 7.

(2012). «New Immigrants: a New Community? The Chinese Community in Peru in Complete Transformation». En C.B. Tan, Routledge Handbook of the Chinese Diaspora. Londres: Routledge.

$164 \frac{\text { PRIMER SEMESTRE } 2016}{\text { MIGRACIÓN Y DESARROLLO NÚM. } 26}$ 
(2000). Sociedades y templos chinos en el Perú. Lima, Perú: Fondo Editorial del Congreso del Perú.

Massey, D., J. Arango, H. Graeme et al. (2000). «Teorías sobre la Migración Internacional: Una Reseña y Una Evaluación». Trabajo, 5.

Ministerio de Relaciones Exteriores, Perú (2014). DC-17-11/11/2014 De cara al futuro a través de la Asociación Asia-Pacífico. Beijing, China. <http://www.rree.gob.pe/ Noticias/Paginas/DC-017-14.aspx>.

Naciones Unidas (2013). International Migration Report 2013. Nueva York: Naciones Unidas.

ORIENTAL, R. (2015). http://revistaoriental.com/visita-protocolar/. 15 de marzo.

Portes, A. y M. Zhou (2013). «El Águila y el Dragón: el papel de las organizaciones transnacionales de inmigrantes en China y México. Migración y Desarrollo, 11 (20).

PosadA, C. (2013). «El tlc Perú-China: Dos años de su entrada en vigencia, resultados y oportunidades». En El TLC Perú-China. Lima: Ministerio de Comercio Exterior y Turismo.

Presidencia de la República (2014). < http://www.presidencia.gob.pe/presidenteshumala-y-xi-jinping-celebran-fortalecimiento-de-la-asociacion-estrategica -integral-entre-peru-y-china $>$.

Pries, L. (2001). New Transnational Social Spaces. Londres: Routledge.

Prom Perú (2013). Guía de mercado China-Sector Servicios. Lima: Prom Perú.

Revista Oriental (1931). Editorial. Oriental (6), 25 de septiembre.

Rodríguez Pastor, H. (1979). La rebelión de los rostros pintados. Pativilca 1876. Huancayo, Perú: Instituto de Estudios Andinos.

(2000). Herederos del Dragón. Historia de la Comunidad China en el Perú. Lima: Fondo Editorial del Congreso.

Smith, M. (2001). Transnational Urbanism: Locating Globalization. Massachusetts: Blackwell.

Smith, M. y L. Guarnizo (1998). Transationalism from Below. New Brunswick: Rutgers University Press.

Sociedad Central (s/n). 1886-1986 Sociedad Central de Beneficencia China y la Colonia China en el Perú. Lima.

Sorensen, N. y L. Guarnizo (2007). «Transnational Family Life Across The Atlantic: The Experience of Colombian and Dominican Migrants in Europe». En N. N. 
Sorensen, Living Across Worlds: Diáspora, Development and Transnational Engagement. Ginebra: International Organization for Migration (Iом).

SteWARD, W. (1976). La servidumbre china en el Perú.Una historia de los culies chinos en el Perú, 1849-1874. Lima: Mosca Azul Editores.

Trazegnies, F. (s/f). «Prólogo». En Sociedad Central de Beneficencia China, 1886-1986. Sociedad Central de Beneficencia China y la Colonia China en Perú, Lima. 